\title{
Novel Endoscopic Management of Colovesical Fistula Secondary to Colonic Diverticular Disease
}

\author{
Murugesh Mallaiyappan ${ }^{1}$ Ganesh Prasad Sankarapandian ${ }^{2}$ Venugopal Sarveswaran ${ }^{3}$ \\ Noufal TB ${ }^{3}$ Jothiprasad Venkatesan ${ }^{3}$ Vishmaya Venugopal ${ }^{3}$
}

1Department of Gastroenterology, Sri Ramakrishna Hospital, Coimbatore, Tamil Nadu, India

2Department of Urology, Sri Ramakrishna Hospital, Coimbatore, Tamil Nadu, India

${ }^{3}$ Depatment of General Surgery, Sri Ramakrishna Hospital, Coimbatore, Tamil Nadu, India

J Digest Endosc 2021;12:46-48.

\author{
Address for correspondence Dr. Noufal TB, DNB \\ (General Surgery) Resident, Sri Ramakrishna Hospital, \\ 395, Sarojini Naidu Road, Sidhapudur, Coimbatore, \\ Tamil Nadu 641044, India (e-mail: noufaltb@gmail.com).
}

\begin{abstract}
Keywords

- colovesical fistula

- colonic diverticulosis

- over-the-scope clip

- combined endoscopy

Colovesical fistula (CVF) is an abnormal communication between bowel and urinary bladder. Most common cause is complicated colonic diverticular disease. The treatment of choice for CVF is surgery. Conservative treatment is reserved for highly selected patients who are unfit for definitive surgery. We report the case of an 86-year-old gentleman with multiple comorbidities, who presented with pneumaturia, fecaluria, and recurrent urinary tract infection. He was diagnosed to have sigmoid colonic diverticulosis with a CVF and was successfully managed with the novel combined endoscopic approach (a simultaneous cystoscopy and flexible colonoscopy), which could be the first to be reported from India.
\end{abstract}

\section{Introduction}

Colovesical fistula (CVF) is a pathological communication between colon, usually sigmoid colon and urinary bladder dome. The incidence of CVF is estimated to be 2 to $4 \%$ with male to female ratio of $3: 1 .{ }^{1}$

The main cause of CVF is complicated diverticular disease in 65 to $79 \%$ of cases, followed by advanced colonic and bladder cancer and Crohn's disease. CVF is suspected clinically based on pathognomonic features such as pneumaturia, fecaluria, and recurrent urinary tract infection (UTI) but can be confirmed by cystoscopy, sigmoidoscopy, barium enema, computed tomography (CT), or magnetic resonance imaging. The treatment of choice for CVF is resection and anastomosis of the involved bowel segment and closure of the bladder either by laparotomy or laparoscopy. Conservative treatment is reserved to highly selected patients who are unfit for surgery.
The development of novel mechanical endoscopic closure systems allows for minimally invasive management of CVF. Only a few cases of endoscopic management by clip closure have been described in the literature. Here, we report a case of CVF, which was successfully managed with over-the-scope clip (OTSC) in collaboration with urologist and medical gastroenterologist.

\section{Clinical Profile}

An 86-year-old gentleman with a history of uncontrolled diabetes mellitus, hypertension, and ischemic heart disease was presented to us with complaints of pneumaturia, recurrent UTI, and occasional passage of feculent material in urine for the last 7 months. Clinical examination was unremarkable except for mild tenderness in the lower abdomen. Investigations showed marked leucocytosis, published online May 26, 2020
DOI https://doi.org/

$10.1055 / \mathrm{s}-0040-1715283$ ISSN 0976-5042.
C2020. Society of Gastrointestinal Endoscopy of India.

This is an open access article published by Thieme under the terms of the Creative Commons Attribution-NonDerivative-NonCommercial-License, permitting copying and reproduction so long as the original work is given appropriate credit. Contents may not be used for commercial purposes, or adapted, remixed, transformed or built upon. (https://creativecommons.org/licenses/by-nc-nd/4.0/).

Thieme Medical and Scientific Publishers Pvt. Ltd. A-12, 2nd Floor, Sector 2, Noida-201301 UP, India 
plenty of pus cells in the urine, and urine culture reported Escherichia coli growth with significant colony count.

Ultrasound scan of abdomen demonstrated some echogenic material in the urinary bladder and an inflammatory mass in the left iliac fossa. For the better delineation of the pathology, we proceeded with contrast-enhanced $\mathrm{CT}$ scan of the abdomen that showed diverticulosis of the sigmoid colon with a CVF (-Fig. 1).

Patient was a very high-risk candidate for anesthesia and his relatives were not willing for surgery due to the risk. But in view of recurrent symptoms, he was planned for OTSC closure of fistula. Unfortunately, due to multiple adjacent diverticula, the exact location of fistulous opening in the colon could not be identified. Then with the help of $20 \mathrm{Fr}$ cystoscope, a 0.28 -inch Terumo hydrophilic guide wire was passed through the opening in the bladder to the sigmoid colon by the urologist. With an adult flexible colonoscope (12.8 mm with $3.2 \mathrm{~mm}$ channel width), a 14/6t size OTSC (Ovesco Endoscopy GmbH, Tuebingen, Germany) was deployed exactly over the fistulous opening by the gastroenterologist ( - Fig. 2; - Video 1).

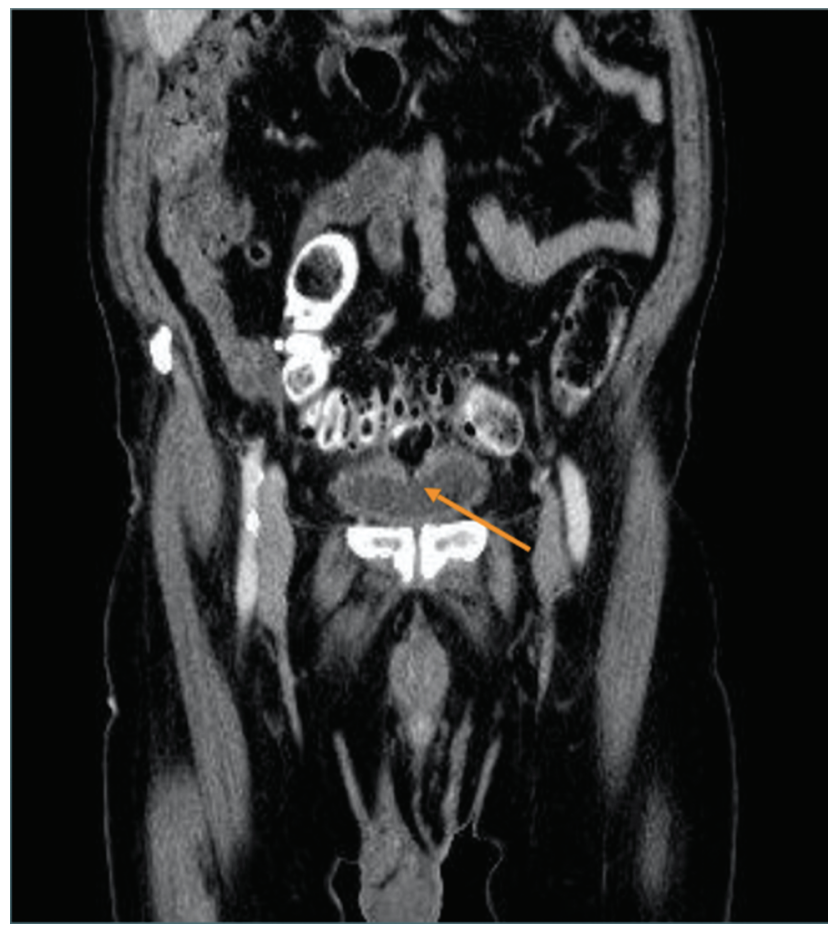

Fig. 1 Contrast-enhanced computed tomography scan of abdomen showing diverticulosis of the sigmoid colon with a colovesical fistula (arrow).
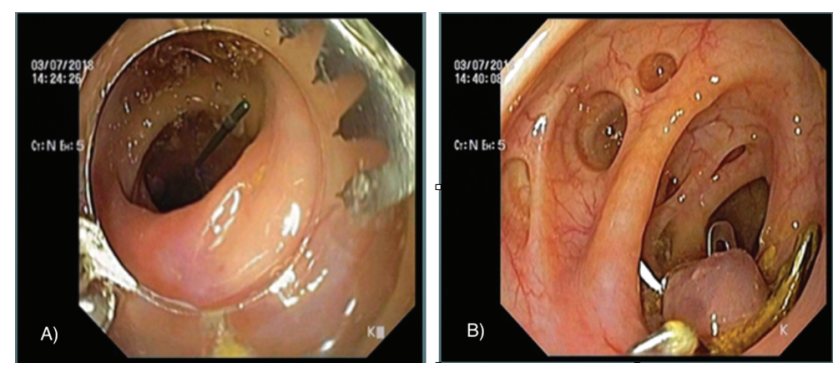

Fig. 2 Colonoscopic pictures showing the guide wire coming through the fistula (A) and over-the-scope clip placement (B).

\section{Video 1}

Guide wire localization and OTSC closure of CVF. Online content including video sequences viewable at: https://www.thieme-connect.com/products/ejournals/ html/10.1055/s-0040-1715283.

Antibiotics were continued, fecaluria and pneumaturia were settled down and he was discharged after 1 week. Urine culture was sterile at 1 month postprocedure and he became symptom free at 18 months.

\section{Discussion}

Enterovesical fistula is a pathological communication between bowel and urinary bladder of which CVF is the most common type with incidence of 2 to $4 \% .{ }^{1}$ The occurrence of CVF is more in male patients when compared with female with a ratio of $3: 1$. This variation could probably be due to the protective effect of uterus in females by acting as barrier between rectum and bladder. ${ }^{2}$

Most commonly, CVF develops as a complication of diverticular disease in 65 to $79 \%$ of cases. In 10 to $15 \%$ of cases, CVF is due to advanced colorectal carcinoma. Other causes are Crohn's disease (9.1\%), surgical trauma (3.2\%), and radiotherapy (3\%). ${ }^{3}$

The diagnosis of CVF is primarily based on clinical evidence. Most common clinical manifestation is pneumaturia reported in 50 to $70 \%$ of cases, followed by fecaluria in $51 \%$, dysuria in $45 \%$, frequency in $45 \%$, urgency and suprapubic pain. Low intravesical pressure favors flow of fecal microbiota into the bladder causing recurrent UTI (45\%), hematuria (22\%), and orchitis (10\%). ${ }^{4}$

CT with both oral and intravenous contrast is the most sensitive investigation to detect CVF with diagnostic accuracy of 90 to $100 \%$. Other investigations include barium enema, cystography, cystoscopy, and colonoscopy. ${ }^{5}$

Surgery is the treatment of choice for CVF. The choice of surgery depends on site and etiology as well as the patient's general condition. The standard surgical strategy consists of resection of the involved bowel tract including fistula, primary or delayed anastomosis, and closure of the bladder either by open approach or by laparoscopy ${ }^{6}$ in patients who are unfit for major surgery due to poor overall health, patients who are unable to tolerate general anesthesia, or in oncologic patients with short life expectancy. A trial of medical therapy including bowel rest, total parenteral nutrition, antibiotics, steroids, immunomodulatory drugs, and urethral catheter drainage or palliative loop colostomy may be warranted., ${ }^{7,8}$

Morbidity from surgery ranges from 25 to 34\%, with a 4.5 to $20 \%$ of perioperative mortality, ${ }^{9}$ which has prompted a search for nonsurgical options like fibrin glue to occlude the fistulous tract, ${ }^{10}$ cautery probe through a specialized cystoscope to coagulate the bladder mucosa around a fistula. ${ }^{11}$ But according to literature, all these methods are effective mostly in upper gastrointestinal fistulas. Due to poor blood supply of colon and due to surrounding 
inflammation, the treatment of CVF is very difficult and surgery is the gold standard treatment. Currently, the indications for treatment with OTSCs are primary or postinterventional bleeding in the gastrointestinal tract, closure of iatrogenic full-thickness or covered perforations. ${ }^{12}$ Even though more expensive than other methods, OTSC can be safely and effectively employed for the treatment of CVF in patients who are unfit for surgery. But its success depends on the exact localization of the fistulous opening. A few cases of endoscopic closure of the colonic side of a CVF using through-the-scope or OTSC have been described in the literature. ${ }^{13,14}$

\section{Conclusion}

We are reporting this case to make the surgical community aware about this previously less described collaborative approach among surgeons, urologists, and gastroenterologists. This combined endoscopic approach, which could be the first to be reported from India, is found to be a safe and effective alternative in patients who are unfit for surgery. However, further studies are needed to validate the potential benefits of this novel endoscopic management.

\section{Funding}

No funding sources.

\section{Conflict of Interest}

None declared.

\section{Ethical Approval}

Not required.

\section{References}

1 Golabek T, Szymanska A, Szopinski T, et al. Enterovesical fistulae: aetiology, imaging, and management. Gastroenterol Res Pract 2013;2013:617967
2 Pontari MA, McMillen MA, Garvey RH, Ballantyne GH. Diagnosis and treatment of enterovesical fistulae. Am Surg 1992;58(4):258-263

3 Yang $\mathrm{CH}$, Liu KH, Chen TC, Chang P-L, Yeh T-S. Enterovesical fistula caused by a bladder squamous cell carcinoma. World J Gastroenterol 2009;15(33):4215-4217

4 McBeath RB, Schiff M Jr, Allen V, Bottaccini MR, Miller JI, Ehreth JT. A 12-year experience with enterovesical fistulas. Urology 1994;44(5):661-665

5 Melchior S, Cudovic D, Jones J, Thomas C, Gillitzer R, Thüroff J. Diagnosis and surgical management of colovesical fistulas due to sigmoid diverticulitis. J Urol 2009;182(3):978-982

6 Desiderio J, Trastulli S, Listorti C, et al. Surgical approach of complicated diverticulitis with colovesical fistula: technical note in a particular condition. Cent Eur J Med 2012;7(5):578-583

7 Amin M, Nallinger R, Polk HC Jr. Conservative treatment of selected patients with colovesical fistula due to diverticulitis. Surg Gynecol Obstet 1984;159(5):442-444

8 Yamamoto T, Keighley MR. Enterovesical fistulas complicating Crohn's disease: clinicopathological features and management. Int J Colorectal Dis 2000;15(4):211-215, discussion 216-217

9 Kirsh GM, Hampel N, Shuck JM, Resnick MI. Diagnosis and management of vesicoenteric fistulas. Surg Gynecol Obstet 1991;173(2):91-97

10 Hedelin $\mathrm{H}$, Nilson AE, Teger-Nilsson AC, Thorsen G, Pettersson S. Fibrin occlusion of fistulas postoperatively. Surg Gynecol Obstet 1982;154(3):366-368

11 Van Thillo EL, Delaere KP. Endoscopic treatment of colovesical fistula. An endoscopical approach. Acta Urol Belg 1992;60(2): 151-152

12 Kirschniak A, Kratt T, Stüker D, Braun A, Schurr MO, Königsrainer A. A new endoscopic over-the-scope clip system for treatment of lesions and bleeding in the GI tract: first clinical experiences. Gastrointest Endosc 2007;66(1):162-167

13 Nawaz F, Ojha H, Ahmed M. PTH-071 Combined endoscopic closure of colovesical fistula. Gut 2019;68:A47-A48

14 Velayos B, Del Olmo L, Merino L, Valsero M, González JM. Nonvisible colovesical fistula located by cystoscopy and successfully managed with the novel Padlock ${ }^{\circledR}$ device for endoscopic closure. Int J Colorectal Dis 2018;33(6):827-829 